\title{
AVALIAÇÃO DA POLÍTICA ESTADUAL DE SANEAMENTO PARA A REGIÃO NORTE E NORDESTE DO ESTADO DE MINAS GERAIS: uma análise do Projeto Vida no Vale ${ }^{1}$
}

\author{
Hygor Aristides Victor Rossoni \\ Universidade Federal de Viçosa (UFV) \\ Erick Brizon D’Angelo Chaib \\ Centro Federal de Educação Tecnológica (CEFET-MG) \\ Leonardo Augusto dos Santos \\ Universidade Federal de Minas Gerais (UFMG) \\ Léo Heller \\ Universidade Federal de Minas Gerais (UFMG) \\ Sonaly Cristina Rezende Borges de Lima \\ Universidade Federal de Minas Gerais (UFMG)
}

\begin{abstract}
AVALIAÇÃO DA POLÍTICA ESTADUAL DE SANEAMENTO PARA A REGIÃO NORTE E NORDESTE DO ESTADO DE MINAS GERAIS: uma análise do Projeto Vida no Vale

Resumo : Visando à análise da Política Pública (PP) orientada para os problemas referentes ao saneamento básico no Norte e no Nordeste do Estado de Minas Gerais, este estudo buscou avaliar a materialização do Projeto Vida no Vale. Para tanto, discute os fundamentos estabelecidos durante a formulação e implementação da Política Estadual de Saneamento Básico. A metodologia empregada na avaliação da PP foi baseada no modelo de objetivos e realizada ex-post, a partir da verificação dos critérios e aspectos referentes à adequabilidade, resolutividade e equidade. Os resultados obtidos mostram que apenas 29,8\% das localidades-alvo foram atendidas até 2011 e que existe um grande atraso na universalização dos serviços de abastecimento de água e esgotamento sanitário. O estudo constata, além disso, que há ausência de controle social e alguns objetivos estabelecidos na documentação do projeto não foram implementados, não permitindo, assim, a disponibilização de importantes informações socioeconômicas e ambientais conforme foi previsto nos resultados do projeto. Palavras-chave: Política pública, Copanor, saneamento básico, salubridade ambiental, Projeto Vida no Vale, Minas Gerais.
\end{abstract}

\section{ASSESSMENT OF MINAS GERAIS POLICY OF ENVIRONMENTAL SANITATION FOR THE NORTH AND NORTHEAST} REGIONS: an analysis of the "Vida no Vale" Project

Abstract: In order to perform an analysis of public policy(pp) concerning sanitation problems in the North and Northeast of Minas Gerais State, this study attempted to assess the materialization of the "Vida no Vale" Project. Thus, it carries out a discussion on the assumptions established during the development and implementation of the State policy of basic sanitation. The methodology used in the evaluation of PP was based on the model of objectives and performed "ex post", through the verification criteria and issues related to suitability, resoluteness and fairness. The results suggest that only $29.8 \%$ of the localities were covered by 2011 , showing delay from the aims of universality, as well as lack of social control based on participatory and shared management, worsened by the difficulty of obtaining information about the financial performance and application of resources. Lack of transparency over produced distortions and asymmetry of information, impacting the assessment possibilities.

Keywords: Public policy, Copanor, sanitation, environmental health, Vida no Vale Project, Minas Gerais State. 


\section{INTRODUÇÃO}

Nos últimos anos, verificou-se certo avanço na cobertura dos serviços de saneamento básico no Brasil, conforme aponta a Pesquisa Nacional de Saneamento Básico (PNSB). Entretanto, a PNSB de 2008 INSTITUTO BRASILEIRO DE GEOGRAFIA E ESTATÍSTICA, 2010, p.37) revela que 12 milhões de domicílios no País ainda não têm acesso à rede geral de abastecimento de água. Apesar do aumento no número de domicílios ligados à rede pública de abastecimento de água entre 2000 e 2008, passando de 63,9\% para 78,6\%, o serviço ainda é deficiente e com distribuição desigual pelo País.

Já os dados relativos ao tratamento dos esgotos são ainda mais preocupantes: apenas quatro em cada dez domicílios brasileiros possuem acesso à rede geral de esgoto (INSTITUTO BRASILEIRO DE GEOGRAFIA E ESTATÍSTICA, 2010). Além disso, pouco mais de um quarto dos municípios $(28,5 \%)$ tratam 0 esgoto coletado. Já em relação ao destino dos resíduos sólidos urbanos, cinco em cada dez $(50,8 \%)$ municípios despejam os resíduos em vazadouros a céu aberto. Apenas $27,7 \%$ dão 0 destino correto, em aterros sanitários (INSTITUTO BRASILEIRO DE GEOGRAFIA E ESTATÍSTICA, 2010).

Quando analisada a cobertura de serviços de saneamento nas áreas rurais, pelo Programa das Nações Unidas para 0 Desenvolvimento (PNUD), foi verificado que 0 Brasil apresenta os piores índices de cobertura se comparados a países africanos e asiáticos. Segundo o PNUD (2010), em 2008, no Brasil, a proporção $(23,1 \%)$ dos moradores rurais atendidos por esgotamento sanitário adequado é inferior à da zona rural do Sudão (24\%), Nepal (24\%), da Nigéria (25\%), do Afeganistão (25\%) e Timor Leste (32\%).

Apesar de constatada uma evolução inquestionável na cobertura dos serviços de saneamento ${ }^{1}$ no Brasil, percebem-se, ainda, grandes déficits regionais, os quais são agravados pela falta de investimento no setor, provocando a deterioração sanitária. Esta situação resulta em diversos impactos sociais, econômicos e ambientais decorrentes da falta de saneamento básico adequado, o que afeta diretamente indicadores de desenvolvimento como saúde, educação, renda e trabalho.

No Estado de Minas Gerais, cerca de $88 \%$ dos domicílios contam com rede de abastecimento de água, sendo que 2,5 milhões de pessoas ainda não possuem água canalizada (FUNDAÇÃO JOÃO PINHEIRO, 2011).

Diante desse dado, verifica-se a necessidade de adoção de políticas públicas ligadas ao saneamento básico que sejam eficientes e eficazes na diminuição das diferenças encontradas regionalmente e que, ao mesmo tempo, sejam adequadas às realidades locais.

Para este presente estudo, foi adotada a seguinte definição para Política Pública:

[...] consiste em um processo, que envolve decisões por parte de corpos e autoridades governamentais, e ações, realizadas por um ator ou um conjunto de atores, e é composto por metas e os meios para alcançá-las. (HELLER; CASTRO, 2007, p. 286).

Neste sentido, 0

[...] saneamento encontra-se na esfera da política pública, uma área de atuação do Estado que demanda formulação, avaliação, organização institucional e participação da população como cidadãos e usuários. (HELLER; CASTRO, 2007, p. 284).

Conforme destacado na literatura (BELLONI; MAGALHÃES; SOUSA, 2003), apesar de sua incontestável importância para verificar os erros e acertos das opções assumidas pelo Estado, e contribuir para eventuais ajustes de rumo, a avaliação das políticas públicas representa uma linha de pesquisa com escassa produção bibliográfica no Brasil (HELLER; COUTINHO; MINGOTI, 2006). Os próprios pesquisadores da área de ciências sociais reconhecem que, ainda que os estudos venham se expandindo, esta área permanece incipiente, com déficit de contribuição efetiva ao conhecimento (TREVISAN; BELLEM, 2008; ARRETCHE, 2003; FREY, 2000).

Nesse contexto, cabe mencionar 0 trabalho de Costa (2003), o qual afirma que 
reconhecer o processo de formulação de uma determinada política setorial e avaliar seu estágio atual é primordial para a busca da efetividade e do cumprimento dos requisitos de promoção da saúde, do ambiente e da qualidade de vida.

Portanto, o presente estudo tem por objetivo levantar os problemas referentes ao saneamento básico existentes nas regiões Norte e Nordeste do Estado de Minas Gerais. Para tanto, procurou-se discutir os fundamentos estabelecidos durante a formulação e a implementação da política de saneamento instituída pelo Projeto Vida no Vale. Diante disso, foi possível: (a) avaliar - 0 processo de implementação da política pública regional de saneamento quanto à pertinência do problema; (b) à consistência interna das suas operações e ações; (c) à suficiência das ações para superar as causas críticas; e (d) à sua confiabilidade.

\section{O PROJETO "VIDA NO VALE"}

O Projeto em análise constitui um esforço do Governo Estadual de Minas Gerais, "[...] com vistas à redução das desigualdades regionais e pautado no modelo de Choque de Gestão." (ANASTASIA, 2009, p. 23)2. No contexto de uma concepção de um Estado para Resultados, segundo o qual o setor público teria a função de gerar resultados socioeconômicos para a sociedade, operacionalmente organizado em Áreas de Resultados, cuja

[...] lógica de ação principal deixa de ser a estrutura organizacional da máquina pública, passando a ter nos destinatários das políticas públicas e nos resultados almejados seu locus de organização. (ANASTASIA, 2009, p. 23).

No âmbito dessa estruturação institucional, e constatada a deficiência quanto à cobertura dos serviços de saneamento regionais, o Governo de Minas Gerais criou 0 Projeto Vida no Vale, com o objetivo de alcançar a universalização dos serviços de abastecimento de água e esgotamento sanitário em sua área de abrangência para todos os habitantes, urbanos ou rurais, de forma que não haja excluídos. Neste sentido, a materialização da proposta de intervenção em saneamento baseou-se na criação de um consórcio entre os Municípios envolvidos e 0 Governo do Estado, sendo que este último concedeu subsídio financeiro para implantação completa dos serviços (MINAS GERAIS, 2007b).

O consórcio, na figura de titular dos serviços de saneamento, firmou contrato de programa com a Companhia Estadual de Saneamento (Copasa-MG), que, por sua vez, atendeu às demandas do Projeto Vida no Vale ${ }^{3}$ com a criação de uma subsidiária para atendimento específico da região. Com isso, foi criada a Copasa Serviços de Saneamento Integrados do Norte e Nordeste de Minas Gerais S/A (Copanor) ${ }^{4}$, subsidiária da Copasa$M G$, tendo como atribuição principal a prestação de serviços de saneamento básico em seus quatro componentes: abastecimento de água, esgotamento sanitário, manejo de resíduos sólidos e de águas pluviais urbanas (MINAS GERAIS; 2007). Em linhas gerais, alguns dos seus objetivos declarados são aumentar 0 índice de atendimento de água e esgoto e reduzir a taxa de mortalidade infantil das comunidades da Região Norte e dos Vales do Jequitinhonha, Mucuri, São Mateus, Buranhém, Itanhém e Jucuruçu (MINAS GERAIS, 2007b).

Quanto ao critério adotado pela CopasaMG para criação da subsidiária, foi priorizado 0 atendimento a 463 localidades com população entre 200 e 5.000 habitantes com os mais baixos Índices de Desenvolvimento Humano (IDH) e maiores déficits em saneamento (MINAS GERAIS, 2009, p. 7).

No que se refere ao Projeto Vida no Vale, há como pressuposto o completo atendimento ao instrumento legal referente à Política Nacional de Saneamento Básico (Lei Federal 11.445, de 5 de janeiro de 2007). Para tanto, em seu termo de referência, foi estabelecida uma série de premissas, relacionadas a seguir, para a promoção e universalização dos serviços de água e esgoto na área de abrangência do Projeto (MINAS GERAIS, 2007b, p. 20): 
- Sustentabilidade dos serviços através de tarifa que cubra os custos operacionais, a depreciação das instalações e a melhora substancial na gestão dos serviços por meio de inovações tecnológicas e operacionais;

- Tarifas flexíveis que garantam o direito à água e que sejam compatíveis com a capacidade a ser paga pelas populações locais;

- Gestão associada, fazendo apelo à participação das populações na coprodução dos serviços, assim como a terceirização de parte destes por meio de desenvolvimento e fomento de parcerias com Cooperativas e Microempresas Locais;

- Recursos humanos da Copasa-MG continuarão trabalhando na prestação dos serviços na região, integralmente absorvidos pelo novo modelo de gestão, de forma que tenham seus direitos adquiridos garantidos (tais como o trabalhista);

- Transparência no processo de gestão: a implementação de avaliações sistemáticas; produção e divulgação de indicadores locais e regionais (funcionamento, desempenho e qualidade dos serviços); e

- implementação de um investimento público não oneroso, pois o mesmo não ocasiona despesas, para viabilizar tarifas compatíveis com a capacidade financeira de toda a população.

Depois de estabelecer as premissas apresentadas, o Governo optou pela adoção de um modelo institucional de gestão associada ao serviço público de saneamento básico, com a justificativa de que absorveria as peculiaridades existentes em cada região, levando em conta a baixa capacidade de pagamento da população local.

A área inicial abrangida pelo projeto era constituída por 92 municípios, 72 distritos e 1.800 localidades, com população total estimada em 1,3 milhão de habitantes, estando 770.000 deles na área urbana e 530.000 na área rural (Tabela 1).

\begin{tabular}{|c|c|}
\hline Características & Descrição \\
\hline Área Total $\left(\mathrm{km}^{2}\right)$ & 86.854 \\
\hline Número de municípios & 92 \\
\hline Número de distritos & 72 \\
\hline População total & 1.265 .222 \\
\hline População nas sedes & 752.426 \\
\hline População nos distritos & 512.796 \\
\hline População urbana & 746.481 \\
\hline População rural & 518.741 \\
\hline $\begin{array}{l}\text { Número habitantes em } \\
\text { localidades rurais remotas }\end{array}$ & 118.000 \\
\hline
\end{tabular}

Fonte: Adaptado de: KAUARK-LEITE, L. et al. Projeto Vida no Vale: universal access to water and sanitation in the North East of Minas Gerais (Brazil). Hydrology and Earth System Sciences, [S. I.], v. 12, p. 1075-1085, ago. 2008.

A atual área de ação da Copanor abrange 88 municípios localizados na Região Nordeste de Minas Gerais e 76 na Região Norte.

Além do objetivo principal da Copanor de observar as diretrizes do Plano de Saneamento Básico estabelecido na Lei Federal $n^{0}$ 11.445/2007, com vistas à universalização do acesso, integralidade dos serviços e demais princípios previstos no art. $2^{\circ}$ da referida lei (BRASIL, 2007), cabe mencionar outros objetivos:

- Implantar sistemas de abastecimento de água, coleta e tratamento de esgoto em todas as localidades com população entre 200 e 5.000 habitantes no Norte e Nordeste de Minas;

- Operar os sistemas de água e esgoto com padrão de potabilidade estabelecidos pela Portaria em vigor do Ministério da Saúde e de acordo com as recomendações da Organização Mundial de Saúde (OMS);

- Praticar tarifas reduzidas em comparação com as cobradas pela Copasa-MG, devido aos subsídios arcados pelo Governo Estadual;

- Melhorar a qualidade de vida da população em sua área de abrangência; - Reduzir os índices de mortalidade infantil causados por doenças infecciosas e parasitárias;

- Reduzir as desigualdades regionais e locais; e 
- Promover a despoluição dos rios e córregos.

Como princípios norteadores de planejamento, foram estabelecidos alguns critérios essenciais à implantação do Projeto, tais como (MINAS GERAIS, 2007b, p. 89-90): i) 0 Projeto deverá ser implantado no período de quatro anos (2007-2010); ii) o valor estimado para a implantação do projeto é de 1 bilhão de reais (incluído todo o investimento); iii) os recursos para implantação serão disponibilizados pelo Tesouro do Estado de Minas Gerais durante 0 período de implementação; e iv) o Estado de Minas Gerais articulará a criação de um consórcio entre si e os 92 municípios no prazo de até 36 meses.

Some-se aos critérios estabelecidos que a subsidiária regional deverá apresentar os indicadores operacionais e de gestão. Na pior das hipóteses, esses indicadores deverão ser semelhantes aos da Copasa-MG após cinco anos de operação, ou seja, ao final de 2011.

Para garantir a sustentabilidade dos serviços prestados, além de recursos do Estado, cerca de $70 \%$ da população na área de atuação da Copanor pagará uma conta mensal entre $\mathrm{R} \$ 5,76$ a $\mathrm{R} \$ 14,40$ (MINAS GERAIS, 2007b).

Deve-se registrar, ainda, que a criação da subsidiária ocorreu no momento em que 0 capital da Empresa foi aberto na Bolsa de Valores, passando a ter caráter não exclusivamente público. Por esta razão, a proposta da criação de subsidiárias foi cercada de reações por parte da sociedade civil, inclusive do Sindicato de Trabalhadores em Água e Esgotos e do Legislativo, tanto que foi levantada a suspeita de que seria uma forma de excluir das contas da Copasa-MG aquelas atividades menos lucrativas e que não atendem os interesses do capital privado que passaria a compor sua matriz acionária.

\section{MÉTOdOS E ARCABOUÇO TEÓRICO- CONCEITUAL DA AVALIAÇÃO}

Para este trabalho, foram realizadas pesquisas bibliográfica e documental a fim de avaliar as propostas e as ações previstas para a implantação da Política Pública de
Saneamento para as Regiões Norte e Nordeste de Minas Gerais. Para tanto, além da caracterização regional, foram analisados 0 resumo executivo do projeto estruturante Vida no Vale (MINAS GERAIS, 2007b) e a formulação, a atuação e a abrangência da Subsidiária Copanor. Foram utilizadas as propostas contidas nos documentos referentes à Trilha de Gestão (MINAS GERAIS, 2009) e na lei de criação - Lei no. 16.698/2007 (MINAS GERAIS, 2007a), bem como os relatórios de desempenho contidos nos cadernos de indicadores do Governo do Estado de Minas Gerais (MINAS GERAIS, 2010; 2011a).

Na Quadro 1, encontram-se registrados e descritos os objetos de avaliação analisados no presente trabalho. Cabe destacar que estes consistem em publicações oficiais, que foram reportadas e analisadas na íntegra por esse estudo.

Segundo Borja e Moraes (2000), a avaliação visa prover as políticas públicas e seus instrumentos (programas, legislações, serviços e/ou instituições) com informações, buscando verificar seu desempenho ao longo do tempo e realizar previsões que possam ser utilizadas para a promoção de ações específicas para otimizar (eficiência e efetividade) o uso de recursos disponiveis e fundamentar a tomada de decisão. Assim, as avaliações que envolvem a análise dos processos de formulação, desenvolvimento, as ações implementadas e/ou os fatos ocorridos, e consequentemente, dos resultados e impactos obtidos e, ainda, do contexto histórico e social em que é concebida, não se restringindo, portanto, ao exame comparativo entre 0 proposto e 0 alcançado (ORGANIZAÇÃO PANAMERICANA DE SAÚDE, 2004).

Em um sentido estrito, a abordagem adotada neste estudo tem 0 objetivo de avaliar e determinar o mérito das ações empreendidas pelos gestores públicos, visando à materialização do Projeto Vida no Vale.

No presente trabalho, adotou-se a definição operacional de avaliação (SOUZA, 2006; FARIA, 2005), entendendo-a como um procedimento sistemático de levantamento e análise dos dados que permitam identificar os resultados, efeitos e/ou impactos do Projeto Vida no Vale. 
Quadro 1 - Definição dos objetos de avaliação e descrição dos documentos oficiais analisados

\begin{tabular}{|c|c|c|}
\hline Objeto de Avaliação & Documento & Descrição \\
\hline Projeto e Plano & $\begin{array}{c}\text { Projeto } \\
\text { Estruturante } \\
\text { "Vida no Vale" }\end{array}$ & $\begin{array}{l}\text { Coordenado pela Secretaria de Estado de Planejamento e Gestão } \\
\text { (Seplag) e pela Copasa-MG, constitui-se em um abrangente } \\
\text { estudo de viabilidade desenvolvido ao longo do ano de } 2006 \text { com } \\
\text { vistas à apresentação de um modelo capaz de implementar } \\
\text { ações, no período de } 2007 \text { a } 2010 \text {, visando à universalização dos } \\
\text { serviços de saneamento nos Vales do Jequitinhonha, Mucuri e } \\
\text { São Mateus - regiões Norte e Nordeste de Minas Gerais (MINAS } \\
\text { GERAIS, 2007, p.17). }\end{array}$ \\
\hline Política & $\begin{array}{c}\text { Lei Estadual } n^{0} \text {. } \\
16.698 / 07- \\
\text { Minas Gerais }\end{array}$ & $\begin{array}{l}\text { Lei de Criação da Copanor: autoriza a Copasa-MG a criar } \\
\text { empresa subsidiária integral com a atribuição de planejar, } \\
\text { projetar, executar, ampliar, remodelar e explorar serviços públicos } \\
\text { de abastecimento de água e de esgotamento sanitário; a coleta, a } \\
\text { reciclagem, o tratamento e a disposição final resíduos sólidos } \\
\text { domésticos e industriais; a drenagem e o manejo das águas } \\
\text { pluviais urbanas, em localidades da região de planejamento Norte } \\
\text { de Minas e das bacias hidrográficas dos Rios Jequitinhonha, } \\
\text { Mucuri, São Mateus, Buranhém, Itanhém e Jucuruçu (MINAS } \\
\text { GERAIS, 2007a, p.1). }\end{array}$ \\
\hline Produto & $\begin{array}{c}\text { Trilha de Gestão } \\
\text { da Copanor }\end{array}$ & $\begin{array}{l}\text { Documento que estabelece diretrizes, procedimentos e } \\
\text { recomendações para padronizar e racionalizar o gerenciamento, } \\
\text { o acompanhamento e a fiscalização das atividades necessárias } \\
\text { para a efetiva implantação dos serviços da Copanor. Dentre estas } \\
\text { podem ser destacadas: a implantação do sistema de } \\
\text { abastecimento de água, de módulos sanitários e do sistema de } \\
\text { esgotamento sanitário (MINAS GERAIS, 2009, p. 9). }\end{array}$ \\
\hline $\begin{array}{l}\text { Performance } \\
\text { (desempenho) }\end{array}$ & $\begin{array}{l}\text { Cadernos de } \\
\text { Indicadores do } \\
\text { Governo do } \\
\text { Estado de } \\
\text { Minas Gerais }\end{array}$ & $\begin{array}{l}\text { Apresenta um conjunto de } 104 \text { indicadores finalísticos pactuados, } \\
\text { segundo modelo de Choque de Gestão - atualizado } \\
\text { recentemente para Gestão pela Cidadania - e o Programa Estado } \\
\text { para Resultados, publicados desde 2009. Os indicadores são } \\
\text { organizados nas } 13 \text { Áreas de Resultados definidas no Plano } \\
\text { Mineiro de Desenvolvimento Integrado (PMDI) denominadas: i) } \\
\text { Educação de Qualidade; ii) Protagonismo Juvenil; iii) Vida } \\
\text { Saudável; iv) Investimento e Valor Agregado da Produção; v) } \\
\text { Inovação, Tecnologia e Qualidade; vi) Logística de Integração e } \\
\text { Desenvolvimento; vii) Desenvolvimento do Norte de Minas, } \\
\text { Jequitinhonha, Mucuri e Rio Doce; viii) Redução da Pobreza e } \\
\text { Inclusão Produtiva; ix) Qualidade Ambiental; x) Defesa Social; xi) } \\
\text { Rede de Cidades e Serviços; xii) Qualidade e Inovação em } \\
\text { Gestão Pública; e xiii) Qualidade Fiscal (MINAS GERAIS, 2011a, } \\
\text { p.8). }\end{array}$ \\
\hline
\end{tabular}

Fonte: (MINAS GERAIS 2007a; 2007b; 2009; 2011a).

Assim, parte-se do pressuposto de que 0 projeto de consolidação da política pública já existe e está em andamento. Isso exclui a avaliação ex ante -, e se caracteriza como uma avaliação ex post.

Já para 0 enfoque de avaliação foi utilizado o modelo baseado em objetivos, 0 qual foi reportado por Worthen, Sanders e Fitzpatrick (2003). Afinal, este método pode ser utilizado quando os objetivos estão claramente definidos e constituem parâmetros explícitos para o trabalho de avaliação.

Finalmente, partindo dessa premissa de avaliação, foram analisados e investigados os critérios e aspectos da Política Pública Regional de Saneamento apontados no Quadro 2. 
Quadro 2 - Critérios e aspectos utilizados na avaliação da atuação da política pública regional de saneamento

\begin{tabular}{|c|l|}
\hline $\begin{array}{c}\text { Critérios } \\
\text { Avaliativos }\end{array}$ & \multicolumn{1}{|c|}{ Aspectos Investigativos* } \\
\hline Adequabilidade & $\begin{array}{l}\text { Ocorreram as mudanças } \\
\text { esperadas? Em que medida o } \\
\text { alcance do resultado resolveu ou } \\
\text { resolverá o problema? }\end{array}$ \\
\hline Resolutividade & $\begin{array}{l}\text { Os resultados esperados serão } \\
\text { adequados às necessidades, } \\
\text { preferências ou valores de grupos } \\
\text { particulares? }\end{array}$ \\
\hline Apropriado & $\begin{array}{l}\text { Os resultados desejados } \\
\text { (objetivos) são realmente valiosos } \\
\text { ou compensadores? }\end{array}$ \\
\hline Equidade & $\begin{array}{l}\text { Os benefícios estão sendo } \\
\text { distribuídos de maneira justa e } \\
\text { compatível com as necessidades } \\
\text { dos usuários? }\end{array}$ \\
\hline
\end{tabular}

Fonte: Dunn (2004, p. 369-385) e Organização PanAmericana de Saúde (2004, p. 112).

Nota: *Adaptação realizada a partir dos trabalhos mencionados.

\section{RESULTADOS E DISCUSSÃO}

Os Vales do Jequitinhonha e do Mucuri, localizados na região Norte e Nordeste de Minas Gerais, têm população estimada em 2,4 milhões de habitantes (FUNDAÇÃO JOÃO PINHEIRO, 2011). Do ponto de vista social, essa região é caracterizada por possuir: baixo índice de escolaridade, pois $29 \%$ das pessoas acima de 15 anos são analfabetas; altas taxas de mortalidade infantil; baixa expectativa de vida; baixa densidade demográfica, intensificada por forte evasão populacional para outras regiões do Estado e outras Unidades da Federação; e, distribuição etária desigual, com grande proporção de crianças e idosos.

As Regiões Norte e Nordeste de Minas Gerais possuem 0 menor Índice de Desenvolvimento Humano Municipal (IDH-M) do Estado de Minas Gerais, com a média de 0,651 (KAUARK-LEITE et al., 2008).

Quanto à agricultura familiar, é 0 segmento demográfico, econômico e cultural mais expressivo, organizado e representativo da região, sendo o que mais tem contribuído para a construção de organizações sólidas, duradouras e de abrangência microrregional. Além disso, é o setor que formula as propostas de desenvolvimento mais abrangentes para a região, seja via associações, sindicatos, conselhos ou Organizações Não Governamentais (ONGs) (MINAS GERAIS, 2007b).

Já os vales dos rios Jequitinhonha, Mucuri e São Mateus apresentavam os maiores déficits de saneamento básico do Estado, correspondentes a índices de atendimento da ordem de $35 \%$ para abastecimento de água, $60 \%$ para esgotamento sanitário e $50 \%$ para coleta de resíduos sólidos (MINAS GERAIS, 2007b).

Do ponto de vista ambiental, as bacias hidrográficas da área de estudo possuem como principais rios o Jequitinhonha e o Mucuri. Estes têm problemas em relação à disponibilidade de recursos, apresentando rendimentos hidráulicos muito reduzidos e um potencial hidrogeológico limitado, associado a aspectos restritivos de qualidade da água subterrânea (ALVIM; FERREIRA, 2007).

Avaliando a concepção do planejamento do Programa, vale ressaltar que, embora a Lei 16.698/07, que criou a Copanor, não preveja critérios, a Empresa estabeleceu como objetivo implantar os sistemas de abastecimento de água e esgotamento sanitário nas comunidades com 200 até 5 mil habitantes, alegando, principalmente, que, apesar de existirem técnicas para prover com soluções de saneamento as comunidades mais longínquas e de baixa densidade populacional, os recursos financeiros são finitos. Por esse motivo, foi adotada a lógica do custo/benefício, que excluiu, deliberadamente, centenas de famílias moradoras de pequenas comunidades com população inferior ao estabelecido.

Devido a denúncias realizadas na Assembleia Legislativa de Minas Gerais (MINAS GERAIS, [2011]), foi possível a formação de uma Comissão de Participação Popular $^{5}$ com a finalidade de cobrar providências da Agência Reguladora de Serviços de Abastecimento de Água e Esgoto de Minas Gerais (Arsae-MG). A referida 
comissão iria investigar as irregularidades na prestação de serviços pela Copanor (tais como falta de regularização fundiária), referentes a obras em estações de tratamento de esgoto e de sistemas de abastecimento de água nos municípios de sua atuação.

Além disso, o Bloco Parlamentar Transparência e Resultado ${ }^{6}$ aponta que apenas 64 localidades, de um total de 463 previstas foram beneficiadas por obras de infraestrutura e atuação em sistemas de saneamento previstos para serem realizados pela Copanor (MINAS GERAIS, [2011]).

Na Tabela 2 é apresentada a evolução dos resultados, referente ao número de localidades atendidas e que têm sistemas em operação em relação ao total de localidadesalvo do Projeto Vida no Vale.

Como pode ser verificado na Tabela 2, e conhecendo-se os prazos estabelecidos no Resumo Executivo do Projeto Vida no Vale, entre o período de 2007 e 2010, a subsidiária da Copasa-MG avançou timidamente rumo aos objetivos pretendidos. Atualmente, constata-se um quadro de baixo alcance de ações. Afinal, a Copanor está presente em apenas $29,8 \%$ das localidades-alvo atendidas em um primeiro momento do projeto.

A partir dos dados obtidos, percebe-se certo atraso no atendimento dos objetivos propostos. Afinal, a Lei $n^{0} 11.445 / 2007$ considera universalização a

Tabela 2 - Percentual de localidades atendidas pela Copanor

\begin{tabular}{ccc}
\hline \multirow{2}{*}{ Ano } & Número de localidades atendidas & $\begin{array}{c}\text { Localidades atendidas (\%), em relação ao total de } \\
\end{array}$ \\
\hline 2007 & 7 & 463 \\
2008 & 22 & 1,5 \\
2009 & 52 & 4,8 \\
2010 & 64 & 11,2 \\
2011 & 138 & 13,8 \\
\hline
\end{tabular}

Fonte: Adaptado de: ALMG (MINAS GERAIS, 2011); e SEPLAG (MINAS GERAIS, 2010, p. 155; [2011]; 2011a; p. 72; 2012, p. 62).

ampliação progressiva do acesso ao saneamento básico para todos os domicílios ocupados (BRASIL, 2007).

Esse fato se deve às sucessivas paralisações nas obras previstas no projeto, as quais foram motivadas por supostas irregularidades e beneficiamento de empresas

responsáveis pela execução e pela fiscalização das obras (MINAS GERAIS, 2011). No relatório elaborado pelo Tribunal de Contas do Estado de Minas Gerais, consta a suspensão de um certame com vistas à contratação de empresa de fiscalização pelo simples fato de apenas uma empresa se habilitar para o processo licitatório (MINAS GERAIS, 2011b).

Essa situação de pouca efetividade apresentada poderia ser explicada pela falta de adoção de modelos mais adequados de planejamento, em que são estabelecidos objetivos, metas, avaliação e atualização. Ressalta-se que este é um instrumento fundamental e imprescindível no processo de formulação e aperfeiçoamento das ações do Estado no campo das Políticas Públicas (ORGANIZAÇÃO PAN-AMERICANA DE SAÚDE, 2004).

Tal observação serve para ressaltar que, pelos princípios do modelo anunciado pelo governo estadual como choque de gestão que se pauta pela eficiência no cotidiano da gestão pública - modelos de planejamento são adotados nas Áreas de Resultados, que se complementam com 0 monitoramento dos respectivos projetos. No caso do projeto na região Norte e Nordeste, estes se encontram na Área de Resultado Vida Saudável e, conforme consta na própria definição de choque de gestão, (ANASTASIA, 2009), toda essa lógica de planejamento e gestão só faz sentido se possibilitar as melhorias desejadas para a sociedade.

Apesar dos resultados desejados pelo Projeto Vida no Vale se aproximarem dos princípios de uma política pública de saneamento que visa à promoção da justiça 
social e ambiental, a resolutividade das ações não vêm produzindo os resultados esperados, uma vez que são deixados de lado componentes importantes do saneamento, como o manejo adequado de resíduos sólidos e das águas pluviais. Tal situação pode soar como contraditória, pois, de acordo com a lei de criação da Copanor, em seu Art. $1^{\circ}$,

[...] cabe à empresa a
atribuição de planejar,
projetar, executar,
ampliar, remodelar e
explorar, inclusive, o
tratamento e disposição
final dos resíduos sólidos
urbano, doméstico e
industrial e drenagem e
manejo das águas
pluviais.
GERAIS, 2009). (MINAS

Tomando por base os dados obtidos durante a fase de diagnóstico na Região (MINAS GERAIS, 2007b, p.47), pode-se dizer que os mesmos reforçam ainda mais esta preocupação, uma vez que foi constatado que o destino dos resíduos coletados era composto por 76 lixões a céu aberto na área de estudo, sendo cinco aterros controlados, cinco usinas de triagem e compostagem licenciadas, sete usinas não licenciadas e dois aterros sanitários em fase de licenciamento.

Além disso, no mesmo levantamento, efetuado pela SEPLAG (MINAS GERAIS, 2007b), constatou-se que apenas 20\% dos municípios da Região possuem estruturas de macrodrenagem. No mais, quando analisado o assoreamento, esse processo foi notificado em $100 \%$ dos municípios da Bacia do São Mateus, $90 \%$ nos do Mucuri e em $36 \%$ dos municípios do Jequitinhonha.

Assim, para a efetiva melhoria da condição sanitária (ORGANIZAÇÃO PANAMERICANA DE SAÚDE, 2004), que se expressa em termos do nível de salubridade ambiental, para a área de estudo, deve-se observar a existência de condições higiênicas das moradias e do espaço público, envolvendo desde as instalações hidráulicas e sanitárias domiciliares e até os sistemas públicos de saneamento básico. Esses sistemas devem ter qualidade e quantidade suficientes para a promoção da saúde pública e controle da poluição ambiental.

Nesse mesmo sentido, como pode ser averiguado pelo estudo de Costa (2003), ao avaliar a Política Nacional de Saneamento, a adequabilidade das condições de saneamento e de moradia representa um grande passivo social no Brasil, uma vez que a melhoria ou a manutenção das condições sanitárias, no espaço interno ao domicílio, ou no seu entorno, reduziria a transmissão das doenças relacionadas ao saneamento inadequado.

Além disso, apesar das propostas de provisão dos serviços - individuais ou coletivos - para o abastecimento de água e esgotamento sanitário previsto pela Copanor possuírem aparente consistência e confiabilidade técnica, não é prevista integração entre ações que envolvam o contexto global para a manutenção e proteção ambiental local, como a educação ambiental, o planejamento e gestão de recursos hídricos e o adequado uso e ocupação do solo.

Assim, a visão descontínua da prestação dos serviços de saneamento, desconsiderando o espaço físico e social e sem integração com outros programas assistenciais e preventivos educação, habitação e saúde - poderá produzir resultados aquém dos esperados.

Da mesma forma, informações sobre as políticas e programas públicos - em termos de quantidade executada e a sua qualidade -, têm sido frequentemente negligenciadas, 0 que dificulta 0 acompanhamento e a verificação pelos atores envolvidos, principalmente a sociedade, impedindo e prejudicando a tomada de decisões em relação às mudanças de direção geral das políticas e ações, de acordo com a demanda local. Isso foi constatado na avaliação do Programa Bahia Azul (PBA), conduzido pela Empresa Baiana de Água e Saneamento (Embasa). Borja (2005) verificou que este programa não foi capaz de promover um serviço de saneamento mais justo do ponto de vista ambiental e social para a população. Dentre os principais motivos apontados, destacou-se a falta de informações e a dificuldade apresentada pela sociedade em participar dos processos de decisão e acompanhamento do referido programa. 
A avaliação de eficiência e eficácia factível e de menor custo - representa um mecanismo necessário e urgente em face da escassez de recursos públicos, o que exige maior racionalização de gastos. Constatou-se que, no Projeto Vida no Vale em análise, não foi previsto um cronograma físico de execução factível na condução das ações, nem tampouco claramente as atividades necessárias para se alcançarem os propósitos estabelecidos. Assim, princípios como justiça social, moralidade, probidade administrativa não puderam ser verificados de forma efetiva.

Vale ressaltar que a avaliação completa do Projeto, de acordo com o Resumo Executivo (MINAS GERAIS, 2007b), estava prevista apenas para verificar a fase final de sua implantação (ao seu final em 2011), por meio de uma equipe independente de avaliação.

Portanto, a falta de avaliação sistemática, desde o processo de formulação da política pública, representa forte risco para 0 sucesso de suas ações, uma vez que os eventuais efeitos (positivos e negativos) serão apenas registrados ao final de sua implantação. Assim, medidas necessárias e importantes para alteração e mudanças de rumo no planejamento não seriam efetivas.

Apesar de não apresentar uma clara indicação quanto ao planejamento da avaliação sistemática e efetiva das atividades e ações desenvolvidas, a Quadro 3 apresenta alguns indicadores que poderiam ter sido utilizados neste procedimento e que certamente iriam possibilitar melhoria gradativa da sustentabilidade na Região, bem como mensurar sua implementação e tentar elucidar os principais fatores que influenciam a prática, provocando mudanças entre o previsto e 0 realizado.

Quadro 3 - Componentes e pressupostos que poderiam ser verificados por meio da avaliação de ações da Copanor nas Regiões Norte e Nordeste de Minas Gerais

\begin{tabular}{|c|c|c|c|c|}
\hline $\begin{array}{c}\text { Tipos de } \\
\text { componentes }\end{array}$ & Objetivos & $\begin{array}{l}\text { Indicadores de } \\
\text { Impacto }\end{array}$ & Fontes de Verificação & Pressupostos \\
\hline $\begin{array}{l}\text { Beneficiários: } \\
\text { População-alvo de } \\
200 \text { a } 5.000 \\
\text { habitantes }\end{array}$ & $\begin{array}{c}\text { Melhoria da } \\
\text { qualidade de vida } \\
\text { e redução das } \\
\text { desigualdades da } \\
\text { população }\end{array}$ & $\begin{array}{l}\text { Taxa de } \\
\text { morbidade e } \\
\text { mortalidade } \\
\text { infantil } \\
\text { causadas por } \\
\text { doenças } \\
\text { infecciosas e } \\
\text { parasitárias }\end{array}$ & $\begin{array}{l}\text { i) Censo demográfico do } \\
\text { IBGE; } \\
\text { ii) Secretarias Municipais; } \\
\text { iii) Sistema de Informações } \\
\text { Hospitalares (SIH); Sistema } \\
\text { de Informações de } \\
\text { Mortalidade (SIM) e Sistema } \\
\text { de Informações de Agravos } \\
\text { de Notificação (SINAN). }\end{array}$ & $\begin{array}{l}\text { Universalização } \\
\text { dos serviços de } \\
\text { água e } \\
\text { esgotamento } \\
\text { sanitário de } \\
\text { qualidade mesmo } \\
\text { em pequenas } \\
\text { localidades rurais }\end{array}$ \\
\hline $\begin{array}{c}\text { Contexto } \\
\text { institucional: } \\
\text { Escritórios } \\
\text { descentralizados e } \\
\text { parcerias entre } \\
\text { órgãos estaduais e } \\
\text { municipais }\end{array}$ & $\begin{array}{l}\text { Planejar, } \\
\text { projetar, } \\
\text { executar, } \\
\text { ampliar, } \\
\text { remodelar e } \\
\text { explorar serviços } \\
\text { públicos de } \\
\text { saneamento }\end{array}$ & $\begin{array}{c}\text { Abrangência e } \\
\text { qualidade dos } \\
\text { serviços } \\
\text { prestados }\end{array}$ & $\begin{array}{l}\text { i) Aplicação de questionário; } \\
\text { ii) Número de moradias } \\
\text { providas de instalações } \\
\text { hidro-sanitárias adequadas }\end{array}$ & $\begin{array}{c}\text { Gestão sustentável } \\
\text { e prática de tarifas } \\
\text { compatíveis com a } \\
\text { realidade local }\end{array}$ \\
\hline
\end{tabular}

Fonte: Elaborado pelos autores. 


\section{CONCLUSÃO}

Apesar de serem constatados avanços quanto à implementação de políticas públicas mediante ações estruturais e estruturantes na questão do Saneamento (abastecimento de água e esgotamento sanitário) nas Regiões Norte e Nordeste de Minas Gerais, ainda se pode perceber discrepâncias em termos de racionalidade das ações de intervenção.

Nesse sentido, verificou-se que, após mais de cinco anos de criação e atuação na região, a Copanor ainda não conseguiu uma ampla efetividade das suas ações.

Além disso, durante a condução do presente estudo, foram encontradas dificuldades para obtenção de informações sobre o desempenho financeiro e a aplicação dos recursos da Copanor. Assim, a falta de transparência acaba por produzir distorções e assimetria das informações, principalmente socioeconômicas, que permitiriam a mensuração do custo-benefício e do custoefetividade das ações propostas para a área de estudo.

No tocante aos principais desafios a serem enfrentados pela Copanor para 0 sucesso das intervenções programadas, estão: a obtenção da sustentabilidade econômica da prestação dos serviços; a adoção de tecnologias viáveis e adequadas à realidade local; o pagamento pelos serviços que devem ser financeiramente suportáveis pela população; e acompanhamento contínuo das ações previstas e seus efeitos na Região.

Ressalta-se que, apesar de possuir 0 nobre propósito de universalizar os serviços de saneamento nas Regiões Norte e Nordeste de Minas Gerais, uma boa governança no setor público inclui fundamentalmente a observação de atitudes e ações que envolvam responsabilidade, transparência e disponibilidade de informações.

\section{REFERÊNCIAS}

ALVIM, A. M.; FERREIRA, G. P. Aspectos Quantitativos e Qualitativos das Disponibilidades Hídricas nas Bacias dos Rios
Jequitinhonha, Mucuri e São Mateus. In: SIMPÓSIO BRASILEIRO DE RECURSOS HÍDRICOS, 17., 2007, São Paulo. Anais... São Paulo: ABRH, 2007. p. 19.

ANASTASIA, A. A. J. Estado para Resultados segunda geração do Choque de Gestão: a ótica do Desenvolvimento no Norte de Minas, Jequitinhonha e Mucuri. In: MINAS GERAIS. Secretaria para Desenvolvimento dos Vales do Jequitinhonha, Mucuri e Norte de Minas. Instituto de Desenvolvimento do Norte e Nordeste de Minas Gerais Redução das Desigualdades Regionais: uma das faces do Choque de Gestão. Belo Horizonte, 2009. p. 21-26.

ARRETCHE, M. Dossiê agenda de pesquisa em políticas públicas. Revista Brasileira de Ciências Sociais, São Paulo, v. 18, n. 51, p. 79, fev. 2003.

BELLONI, I.; MAGALHÃES, H.; SOUSA, L. C. Metodologia de avaliação em políticas públicas. São Paulo: Cortez Editora, 2003.

BORJA, P. C. Programa Bahia Azul: uma avaliação quali-quantitativa. Cadernos PPGAU/UFBA, Salvador, v. 4, n. 1, p. 11-36, abr. 2005.

; MORAES, L. R. S. Indicadores de saúde ambiental - saneamento em políticas públicas: análise crítica e proposta. In: CONGRESO INTERAMERICANO DE INGENIERÍA SANITARIA Y AMBIENTAL, 27., 2000, Porto Alegre. Anais... Porto Alegre: ABES, 2000. p. 17.

BRASIL. Ministério das Cidades. Secretaria Nacional de Saneamento Ambiental. Proposta de Plano Nacional de Saneamento Básico PLANSAB.. Brasília, DF, 2011.

Presidência da República. Lei 11.445, de 5 de janeiro de 2007. Estabelece diretrizes nacionais para o saneamento básico. Diário Oficial da União, Brasília, DF, 2007. Seção 1. p. $3 . \quad$ Disponível em:<https://www.planalto.gov.br/ccivil_03/_ato2 
007-2010/2007/lei//11445.htm>. Acesso em: 1 jun. 2011.

COSTA, A. M. Avaliação da política nacional de saneamento, Brasil - 1996/2000. 2003. 248 f. Tese (Doutorado em Saúde Pública) Centro de Pesquisas Aggeu Magalhães, Escola Nacional de Saúde Pública, Fundação Oswaldo Cruz, Recife, 2003.

DUNN, W. N. Public Policy Analysis: an introduction. 3. ed. Upper Saddle River, NJ: Pearson Prentice-Hall. 2004.

FARIA, C. A. P. A política da avaliação de políticas públicas. Revista Brasileira de Ciências Sociais, São Paulo, v. 20, n. 59, p. 97-169, out. 2005.

FREY, K. Políticas públicas: um debate conceitual e reflexões referentes à prática da análise de políticas públicas no Brasil. Planejamento e Políticas Públicas, Brasília, v. 21, p. 211-59, Jun. 2000.

FUNDAÇÃO JOÃO PINHEIRO. Planilha com os valores da População de Minas Gerais: Censo 2010. Belo Horizonte, 2011. Disponível em:

$<$ <ttp://www.fjp.gov.br/index.php/servicos/82servicos-cepp/1263-populacao-de-minasgerais-censo-de-2010>. Acesso em: 1 jun. 2011.

HELLER, L.; CASTRO, J. E. Política pública de saneamento: apontamentos teóricoconceituais. Engenharia Sanitária e Ambiental, Rio de Janeiro, v. 13, n.3, p. 284295, jul./set. 2007.

; COUTINHO, M. L.; MINGOTI, S. Diferentes modelos de gestão de serviços de saneamento produzem os mesmos resultados? Um estudo comparativo em Minas Gerais com base em indicadores. Engenharia Sanitária e Ambiental, Rio de Janeiro, v. 11, p. 325-336, out./dez. 2006.

INSTITUTO BRASILEIRO DE GEOGRAFIA E ESTATÍSTICA. Pesquisa Nacional de Saneamento Básico - 2008. Rio de Janeiro, 2010.
KAUARK-LEITE, L. et al. Projeto Vida no Vale: universal access to water and sanitation in the North East of Minas Gerais (Brazil). Hydrology and Earth System Sciences, S. I.], [V. 12, p. 1075-1085, ago. 2008.

MINAS GERAIS. Assembléia Legislativa de Minas Gerais. Arsae recebe denúncias sobre serviços da Copasa e Copanor. Belo Horizonte, [2011]. Disponível em:<http://www.almg.gov.br/not/bancodenoticia s/not_837456.asp>. Acesso em: 01 jun. 2011.

Integrado

Copasa Serviços de Saneamento Norte e Nordeste de Minas Gerais S/A. Trilha de Gestão para projetos, materiais e obras da Copanor. Belo Horizonte, 2009. Não paginado.

Lei 16.698, de 18 de abril de 2007. Autoriza a Companhia de Saneamento de Minas Gerais - Copasa-MG - a criar empresas subsidiárias nos termos que especifica. Diário do Executivo do Governo de Minas Gerais, Belo Horizonte, 2007a. p.1. col.1.

Secretaria de Estado de Planejamento e Gestão. Projeto Vida no Vale: universalização do abastecimento de água $e$ esgotamento sanitário no Nordeste de Minas Gerais, Vales do Jequitinhonha, Mucuri e São Mateus - resumo executivo. Belo Horizonte, 2007b.

Caderno de Indicadores 2010: indicadores da gestão por resultados do governo do Estado de Minas Gerais - Programa Estado para Resultados. Belo Horizonte, 2010.

Caderno de Indicadores 2011: indicadores da gestão para cidadania do governo de Minas Gerais. Belo Horizonte: Escritório de Prioridades Estratégicas, 2011a. (Caderno de Indicadores).

Caderno de Indicadores

2012: indicadores da gestão para cidadania do governo de Minas Gerais. Belo Horizonte: 
Escritório de Prioridades Estratégicas, 2012. (Caderno de Indicadores).

Tribunal de Contas. Relatório de Dados do Processo $n^{\circ} 77546$. Belo Horizonte, $2011 b$. Disponível em:<http://www.tce.mg.gov.br/pesquisa_proces so.asp>. Acesso em: 21 mai. 2011.

ORGANIZAÇÃO PAN-AMERICANA DE SAÚDE. Avaliação de Impacto na Saúde das Ações de Saneamento: marco conceitual e estratégia metodológica. Brasília, DF: Ministério da Saúde, 2004.

PROGRAMA DAS NAÇÕES UNIDAS PARA O DESENVOLVIMENTO. $4^{\circ}$ Relatório Nacional de Acompanhamento dos Objetivos de Desenvolvimento do Milênio. Brasília, DF: IPEA, 2010.

SOUZA, C. Políticas Públicas: uma revisão da literatura. Sociologias, Porto Alegre, ano $8, n$. 16, p. 20-45, jul./dez. 2006.

TREVISAN, A. P.; BELLEN, H. M. Avaliação de políticas públicas: uma revisão teórica de um campo em construção. Revista de Administração Pública, Rio de Janeiro, v. 42, n. 3, p. 529-550, maio./jun. 2008.

WORTHEN, B. R.; SANDERS, J. R.; FITZPATRICK, J. L. Program evaluation, alternative approaches and practical guidelines. 3. ed. New York: Addison Wesley Longman, 2003.

\section{NOTAS}

1 Os autores agradecem ao Conselho Nacional de Desenvolvimento Científico e Tecnológico (CNPq) pela concessão do auxílio - bolsa de estudo de doutorado: $\mathrm{GD}$ - ao primeiro autor.

2 Para a caracterização do atendimento e do déficit de acesso ao saneamento básico no Brasil, durante a elaboração do Plano Nacional de Saneamento Básico (Plansab), buscou-se uma definição para a análise situacional levando em conta a infraestrutura implantada, os aspectos socioeconômicos e culturais e a qualidade dos serviços ofertados ou da solução empregada. Neste sentido, os diferentes componentes do saneamento podem ser classificados em relação ao atendimento em: adequado; precário e sem atendimento. Para mais informações consultar 0 estudo que deu origem ao Plansab (BRASIL, 2011).

${ }^{3}$ Choque de Gestão foi uma política de governo proposta por Aécio Neves durante o seu mandato como governador de MG (2002/2006 - 2006/2010) que, num primeiro momento, visou ao ajuste e à racionalização do setor público estadual.

${ }^{4}$ Cabe destacar que a área inicialmente abrangida pelo Programa Vida no Vale era composta por 92 municípios que pertencem a distintas regiões administrativas existentes no Estado de Minas Gerais. A maioria dos municípios considerados encontra-se na Região de Planejamento Jequitinhonha/Mucuri (64 municípios), seguidos do Norte de Minas (12), do Rio Doce (10) e da Região Central (5). No entanto, ao criar o consórcio entre os municípios e a subsidiária da Copasa-MG, foi definido como escopo de atuação da empresa as regiões geográficas Norte e Nordeste do Estado de Minas Gerais.

${ }^{5}$ A Lei Estadual no. 16.698, de 17 de abril de 2007, autorizou a Copasa-MG a criar a subsidiária Copanor.

6 Tem como missão aumentar a intervenção da sociedade na agenda e no planejamento públicos. Compete à Comissão: i) apreciar sugestões para aprimorar os trabalhos legislativos; ii) receber e encaminhar proposta de ação legislativa; iii) acompanhar a tramitação de uma proposta de ação legislativa apresentada pela sociedade; iv) promover estudos, pesquisas e debates ou realizar consulta pública sobre assunto de interesse geral.

7 Aliança entre dois ou mais partidos políticos que passam a atuar na Casa Legislativa como uma só bancada, sob liderança comum. Em Minas Gerais, reúne partidos políticos na Assembleia Legislativa e tem como objetivo atuar na defesa dos direitos do cidadão e na discussão e apresentação de projetos que melhorem a vida dos mineiros.

\section{Hygor Aristides Victor Rossoni}

Engenheiro Ambiental

Doutorando do Programa de Pós-Graduação em

Saneamento, Meio Ambiente e Recursos Hídricos da Universidade Federal de Minas Gerais (UFMG)

Professor do Instituto de Ciências Exatas e Tecnológia do Campus Florestal da Universidade Federal de Viçosa (UFV)

E-mail: rossoni@ufv.br ou rossoni@ufmg.br

\section{Erick Brizon D’Angelo Chaib}

Engenheiro Civil

Doutorando do Programa de Pós-Graduação em

Saneamento, Meio Ambiente e Recursos Hídricos da Universidade Federal de Minas Gerais (UFMG) 
Professor do Centro Federal de Educação Tecnológica

(CEFET-MG)

E-mail: erick@timoteo.cefetmg.br

ou erickbrizon@gmail.com

\section{Leonardo Augusto dos Santos}

Engenheiro Civil

Mestre em Saneamento, Meio Ambiente e Recursos

Hídricos pela Universidade Federal de Minas Gerais

(UFMG)

E-mail:

soldier@ufmg.br ou leoaugusto.engcivil@gmail.com

\section{Léo Heller}

Engenheiro Civil

Doutor em Epidemiologia

Professor titular do Departamento de Engenharia

Sanitária e Ambiental da Universidade Federal de Minas

Gerais (UFMG)

E-mail: heller@desa.ufmg.br

\section{Sonaly Cristina Rezende Borges de Lima}

Engenheira Civil

Doutora em Demografia pelo Centro de Desenvolvimento e Planejamento Regional da Universidade Federal de Minas Gerais (UFMG)

Professora adjunta da Escola de Engenharia da

Universidade Federal de Minas Gerais (UFMG)

E-mail: srezende@desa.ufmg.br

\section{Universidade Federal de Viçosa - UFV}

Avenida Peter Henry Rolfs, s/n - Campus Universitário, Viçosa/MG

CEP: $36570-000$

\section{Centro Federal de Educação Tecnológica - CEFET- \\ MG}

Av. Amazonas 5253 - Nova Suiça - Belo Horizonte/MG CEP: $30.421-169$

\section{Universidade Federal de Minas Gerais - UFMG}

Campus Pampulha - Avenida Antonio Carlos 6627 - Belo

Horizonte/MG

CEP: $31270-901$ 